Practising Critical Resilience as an Advanced Peer Support Worker in London: a Qualitative Evaluation of a Peer-led Hepatitis C Intervention Amongst People Experiencing Homelessness Who Inject Drugs.

Julian Surey $^{1,2}$, Marie Francis ${ }^{1,2}$, John Gibbons ${ }^{2,3}$, Mark Leonard ${ }^{2,3}$ Ibrahim Abubakar $^{1}$, Alistair Story ${ }^{2,4}$, Jennifer MacLellan ${ }^{5 *}$

${ }^{1}$ Institute of Global Health, University College London, UK,

${ }^{2}$ Find and Treat, UCLH NHS Trust, London, UK,

${ }^{3}$ Groundswell, London, UK,

${ }^{4}$ Collaborative Centre for Inclusion Health, University College London, UK

${ }^{5}$ Nuffield Department of Primary Care Health Sciences, University of Oxford, UK.

*corresponding author: jennifermaclellan@phc.ox.ac.uk 


\title{
Practising Critical Resilience as an Advanced Peer Support Worker in London: a Qualitative Evaluation of a Peer-led Hepatitis C Intervention Amongst People Experiencing Homelessness Who Inject Drugs.
}

\begin{abstract}
Background: Peer support has been used as a mechanism to facilitate active engagement with healthcare among underserved populations. The HepCare project upskilled experienced peer support workers (PSWs) to become equal members of a service provider team, taking on advanced clinical roles normally carried out by medical or nursing specialists.
\end{abstract}

Method: A participatory case study approach was taken to the study following the methodological guidance of Merriam (1998). The subject of the case in our study is the advanced peer support workers (APSWs) functioning in the HepCare project as service providers. The object of the case is an exploration of their transition to service provider in the HCV screening and treatment support service. Five peer led in-depth interviews with APSWs were supplemented by a survey of health professionals, interviews with service users, documentary evidence in the form of job descriptions, observational notes and a blog from the field. Thematic analysis of the data was conducted, refined and finalised in a workshop with the research team and APSW participants.

Results: Three themes were generated from the data that explore the peer support worker's transition to APSW in the programme: Transition to Integration, Retaining 'Peerness', and Practising Critical Resilience. The advocacy and support enacted by the APSWs through the HepCare project, offer purpose and meaning alongside integration into a new social group. This is buffered by the supportive context of the programme and facilitates a motivating sense of worth. 
Conclusion: The programme offers policy guidance for the structured career development of APSWs and a platform for enactment of critical resilience as they transition to their advanced role, in the healthcare provider team.

\section{Key words: Underserved populations, Peer support workers, Critical resilience,}

\section{Hepatitis C}

\section{Introduction}

Underserved populations (people experiencing homelessness, people who inject drugs (PWIDs) and prison populations) whilst most at risk of Hepatitis C virus (HCV), encounter the biggest challenges to access testing, care and treatment. Peer support has been used as a mechanism to facilitate active engagement with healthcare among underserved populations, fostering harm reduction and the promotion of health benefits (Kerr et al 2006, Sherman et al 2008, Kennedy et al 2019). Peer support workers (PSWs), with their lived experience of a lifestyle or condition, can share similar experiences or characteristics with the target intervention group. This can give them a connection that enables them to support others facing similar challenges and advocate for improved health and wellbeing among people who use drugs (Kerr et al 2006, MacLellan et al 2015, Jozaghi et al 2018, Kennedy et al 2019). Peers are typically recruited from within the client pool of a service and are usually given some basic training for the role of offering support to other individuals, to aid their journey to recovery or treatment completion (Mowbray 1998, Hegedus et al 2020). This support could take the form of helping people attend their appointments, take their medication or change their lifestyle to optimise their recovery. The flexibility of peer work can present an opportunity to re-enter the labour market for a group that can struggle with the responsibility of fixed employment (Kennedy et al 2019, Hegedus et al 2020, Miler et al 2020). However 
this volunteer role is characterised by instability and insecurity (Greer et al 2020, Otte et al 2020).

The HepCare project aimed to develop models of care that link primary, secondary, outreach and community care with treatment for underserved populations at risk of $\mathrm{HCV}$ across four EU sites (Ireland, UK, Spain, and Romania). Within HepCare, London led on the 'HepFriend' work package, to develop a sustainable career progression opportunity from traditional peer support work. It used experienced PSWs hosted by and trained in homeless health advocacy by a partner charity organisation, to increase awareness of HCV in at risk underserved populations, promote screening and provide linkage to care with treatment support. This established team of PSWs co-wrote a job description with the project lead, graded and paid at NHS band 3, for an advanced role. This incorporated training in active case finding, blood-borne virus (BBV) testing using point-of-care tests (POCTs), liver fibrosis assessment, referring to secondary care and treatment support. These upskilled peers became advanced peer support workers (APSWs), trained on the job using a competency framework designed specifically for the role. New APSWs commenced their advanced training by shadowing the nurse in the clinic doing the screening and tests. They practiced these tasks in role play scenarios before working directly with clients under supervision. The level of supervision, support and time taken to competence was guided by the confidence and ability of the APSW, supplemented by online competence training from the test manufacturers. Regular reflection with the project nurse supported their achievement of competence and ongoing development.

The APSWs were equal members of the service provider team and fully paid commensurate to their role at NHS band 3 or NHS Band 4 for the senior APSW co-ordinating treatment referral and follow up with secondary care. For context, in the UK a newly qualified nurse starts at a NHS Band 5. The rationale for using APSWs in this way is to improve both the 
reach of the HCV service, and engagement with care among the client base based on the unique skills of their PSW role. Enhancing those skills with practical tasks and appropriate remuneration offers a structured career development opportunity to this cadre rather merely an example of task shifting (Mijovic et al 2016, Mundeva et al 2018). Not all PSWs took up the opportunities offered by the APSW role, with one applicant leaving after a few months due to personal circumstances. However those APSWs who completed the training and moved to supporting the new APSWs joining the programme expansion, cited confidence in their recovery and motivation for promotion as key drivers in their engagement with HepCare's supportive route in to main stream, salaried employment.

The integration of peer support workers into healthcare provider teams in such an 'assistant practitioner' role in BBV services is novel. Liminality of occupational identity, barriers of power in the 'peer' relationship and concerns of identifying with underserved populations to a new occupational group have been cited as concerns in other examples of paid peer support (Simpson et al 2018, Walsh et al 2018, Otte et al 2020). However, the HepFriend model is not just a salary for peer support. It offers an effective screening and treatment support model for underserved populations and career opportunities for the peer support worker cadre. This evaluation aimed to chart the experience of APSWs operating in this enhanced role, provide guidance for other services when designing similar interventions, and influence wider policy.

\section{Method}

A case study approach was taken following the methodological guidance of Merriam (1998). She advocates a 'case' to be a phenomenon occurring in a bounded context. This can be applied to a program, institution, person, process or social unit. Her three conditions of a case study design are that it is particularistic, descriptive and heuristic, thereby illuminating the phenomenon under study for the reader. The subject of the case in our study is the APSWs 
experience of functioning in a service provider role, while the object of the case is an exploration of their transition to service provider in the HCV screening and treatment support service of HepCare. To explore the experience of transition from 'street' to 'institution', we enlisted those with the lived experience of that transition. Using one of the peers as interviewer and all participants in analysis, we aimed to enlist inside knowledge of the multiple vulnerabilities they face (Devota et al 2016). This would mitigate against the potential blind spots of the research team who are insulated from the reality of transitioning from membership of an underserved population to that of a care provider (Damon et al 2017, Green 2017).

Participatory APSW interview data was supplemented by interviews and surveys from service users, healthcare providers who had experience of working with the HepCare team, job descriptions, observational notes and a blog from the field. Ethical approval for this qualitative study was granted by the Institutional Review Board of North-West Haydock Research Ethics Committee, London, UK.

\section{APSW interviews}

Five APSWs were invited to participate in the study through convenience sampling from a full time APSW of the project, and thus were self-selecting. Initially, a single semi-structured interview designed in collaboration with the APSWs of the HepCare project was conducted by a research nurse experienced in qualitative interviewing, on neutral premises with the primary full time APSW. This APSW then conducted the same semi-structured interview with four of his APSW colleagues in HepCare, with support from the research nurse in the team. Interviews lasted between 60 and 90 minutes, were recorded and transcribed verbatim. Interview content was kept confidential among interviewees, with all identifiers removed during write up. Participants were given pseudonyms to protect anonymity. 


\section{Service user interviews}

In-depth, semi-structured interviews were carried out with 10 patients who accessed services through HepCare as part of a qualitative evaluation of the project. Patients were recruited by purposeful sampling to ensure the sample had all received, or were in the final weeks of their treatment. Interviews were structured and included: Perspectives on the service in its ability to engage underserved $\mathrm{HCV}$ positive individuals in the community; how the outreach services may have impacted referral, engagement, retention, or adherence along the continuum of care; experience of using the service and any comparisons with the standard of care. The interviews were audio recorded and transcribed verbatim.

\section{Service provider perspectives}

Service providers who had a long-standing connection with the project were interviewed. Providers were specialist prescribers from the sexual health and infectious disease team (1) or nurses based in community - primary care blood born virus nurses (2) or secondary care hepatology clinical nurse specialists (2). All had been receiving referrals from the HepCare team and peer accompanied service users for at least three years. The HepFriend lead, with more than five years' experience working in peer support co-ordination was also sampled. They were asked about the value of working with peers; how acceptable peer support is for service users; what colleagues thought and recommendations for improvement.

\section{Additional information sources}

Documentary evidence in the form of job descriptions, and observational notes were used to supplement the interviews. Job descriptions were taken from the host peer organisation charities that employed the PSWs, and those co-written for the HepCare APSW programme. 


\section{Data synthesis and thematic analysis workshop}

A thematic analysis was conducted across all the data in a consultation workshop with the core research team, which included experienced qualitative researchers, research nurses, the project lead and peer support workers (JS, MF, JG, JM, ML). Initial coding was discussed, and interpretive themes were named and refined in the group. The constructed framework of the data was returned to the APSW interviewees, discussed in relation to their transition experience and adjusted accordingly. The research team felt this produced an authentic, democratic explanatory framework of the PSW transition experience to APSW in the enhanced HepCare role (Devotta et al 2016, Jozaghi et al 2018).

\section{Results}

The five APSWs were interviewed between March and October 2019. Participants were all male, aged between 32 and 60 with between two and ten years of peer advocacy experience in different charity organisations. All had experienced homelessness in their recent history, accompanied by substance misuse and mental health challenges. There was also personal experience of hepatitis $\mathrm{C}$ infection within the sample. All participants had intimate knowledge of stigma directed against them and barriers to accessing health and social care support.

From the participatory analysis of all data collected, it was clear that the values and design of the HepCare programme reflected the same core principles of inclusion and equality as the peer advocacy agencies from where the APSWs were recruited. Furthermore, in comparison with a PSW, the APSW builds on the core engagement skills to develop their role in technical and management tasks. These include BBV testing and pre-treatment assessments, management of workload and planning of the screening site schedule, onward referral of clients to the clinical team as well as involvement in HCV training, advocacy, conference 
attendance and presentation. This APSW role is asking a high level of commitment, reliability, communication agility and skill acquisition. This experience is presented under the three themes of Transition to Integration, Retaining 'Peerness', and Practising Critical Resilience.

\section{Transition to Integration}

The high expectation of the advanced role is accepted by the APSWs as an opportunity for progression:

"So going through the process of getting training and qualifications I just felt confident and more self-assured." Peer 3 (P3)

"It's a good feeling actually I really enjoy the responsibility. There's a lot more responsibility cos Ifeel like it's in my hands. ” Principle Peer (PP)

And is clearly reflected in their attitude in the team as seen from a description of the APSWs by the programme lead,

“... [they are really] in with the idea. They really believe in it” (HepCare UK Lead)

However, there was open acknowledgement of the variety of starting places of the peer cadre. This led to a request for understanding on the part of the employer due to the risk of relapse as new pressures are applied:

"I think closer supervision maybe ward it [relapse] off but you would need to get the right person in to be doing that sort of supervision. I think everything is a trigger if you believe in that, I'm not much of a fan of the trigger model, I just think everything's a trigger, get on with it." Peer $1(\mathrm{P} 1)$ 
But I've also seen people who have relapsed but haven't had the ability to take ownership of that. They created a lot of chaos for themselves. When they might have felt that they've been treated quite badly when really it was about their own inability to be honest." $\mathrm{P} 3$

“my relapses were important because I learned a little bit from each one, ” PP

While the health providers who worked with the APSWs fundamentally supported their involvement and integration into the care team, there was an expectation of conformity to professional norms in the hospital setting. This was not always sensitive to the peer approach or context and the need for some adjustment in the service provision model in secondary care to accommodate non-medical personnel within the service was acknowledged. For example, comments had been made regarding expected styles of personal dress or presentation, time commitment, experience in the skill base and communicative agility. However, as the programme lead explained:

“He's doing three different jobs...we've got to slowly introduce the HepC stuff and then he will take over... and part of being a 'peer' is getting on a level with the punters*” (HepCare UK Lead) *punter - Informal British phrase for customer or client

Within a community context where working practices are more context specific, a relaxed and facilitatory approach was taken that did not solely focus on the client as the objective of activity. The confidence and skill development of the APSW was an equally important focus of the programme: 
"Some of us peers have no or very little education and a career seems a million miles away. Being trusted with the responsibility for others is massive. It helps us to develop key skills to move on with our lives." (APSW blog)

This understanding of the APSW role as a transition experience guided interaction and workflow between the nurses of HepCare and the APSWs.

"We have a very flat hierarchy, the nurses teach the practical stuff in clinic and they see it's not a mystery and their confidence evolves. There is no light bulb moment. Things fall in to place... we give them time and when they are familiar they get their hands on it." (HepCare nurse)

Acceptance of efforts to include the APSWs as part of the team was facilitated by the inclusive approach of the HepCare programme:

"I don't know what the word is but it does make me feel part of the team because you are surrounded by nurses all day and really smart people, it can be quite intimidating but it does make me feel more a part of it, that I am playing more of a role than just being a peer." (PP)

Meanwhile the benefit to the client, to attendance, and treatment adherence was overwhelmingly positive from secondary care providers, despite confusion regarding the extended role and associated terminology of the APSW in comparison to peer advocates.

"Working with peers is extremely valuable and has become an integral part of the clinics we provide. Information peer support workers bring back from patients have added to clinical decisions taken and sometimes it has been a team discussion on how to facilitate treatment in the best way. "(Hepatologist A) 
There were requests for greater involvement and formalisation of the APSW role within the hospital system to include the APSWs within medical case management meetings, to be present in clinic to engage with clients and to deliver education and workshops jointly with clinicians. This suggests a view of the APSW by the clinicians as a facilitator of care provision rather than as an outside agent advocating for care provision. This 'in-group' perception is shared in a blogged description of the APSW service by one of its members:

"Dedicated peer case workers can remove these barriers to care. We can case manage through treatment and work closely with the nurses and clinical teams to ensure that everyone knows where they need to be and when they need to be there." (Blog 2)

The health providers clearly described the value of the case workers and their inclusion in the team. In return the APSWs appeared to reflect a sense of connection and belonging with the care provider team.

\section{Retaining 'peerness'}

While the APSWs described feeling more integrated, there was a clear sense of identity and purpose in their role, and awareness of their strengths in creating a bridge between two worlds:

"I think that it's just being obviously friendly and being able to build trust or put confidence in people quickly. When you are meeting people, those first impressions are always very important to build connections with hospital staff or keyworkers at a hostel. Being personable is key.” PP 
"Empathy is key to being effective in the role. Training, experience-of having been a marginalised person. "I don't forget where I came from even if I'm not there” P1

"They don't look at the clients holistically. I have told doctors they are wrong, for example when patients have been denied hep C treatment if they're still drinking." Peer 4 (P4)

This co-ordinating position is also seen as a strength by the interviewed service users as they try to navigate their care landscape:

"(the APSW) come up and said to me I'll get (the nurse) to see you even if you aint got an appointment. Even down to that. Cause he gets on well with her, .... that nurse, so he can go and talk to her a bit on a level more than, like so official........ he's on a level you can talk to...... cause they've either been around it or they know someone who's been through it you know what I mean. "Service user 1 (SU1)

Previous work in peer relationships has highlighted the value of a non-judgemental communication approach by the peer and the trust gained by sharing their lived experience. The APSWs integration into the formal, salaried care provider team did not appear to impact their 'peerness'.

"[the case workers] make you feel like they cared instead of the complete opposite being made to feel like shit. And [the Caseworker] didn't look down on you at all" (SU2)

"he was very good very good man. And he's easy he's ideal, and it is speak to you like, like as if you're not a prick, just a normal person." (SU2)

“They're textbook people, they've only read out of a textbook like with rules like and people think now you don't know what you're talking about they don't take it in, like 
honestly in one ear and then out the other, but when you have a user, an addict or was an addict tell you, you believe them, honest to god you do" (SU5)

The APSWs in their new role still valued the shared experience of adversity as a key to their role. Despite concern in the literature, they did not feel disclosure restricted them, even advocating more openness:

“A lot of people won't disclose the fact that they have a substance misuse background and the difficulty is owning that stuff. Having a clear relapse policy as part of someone's contract would help. And highlighting and celebrating the fact that people are in recovery, rather than having secrecy about it. Having a point of contact where people can go. Employee assisted programmes. These things aren't highlighted enough."P3

The openness about their challenging background also served to highlight their own need for support with the risks they are exposed to, from both the context and responsibility of their role.

\section{Practising Critical Resilience}

The quality of lived experience was not presented as a defence against perceived negative perceptions by service providers, but as an enabler for the APSW to fulfil their function as advocates and care pathway navigators in the multi-disciplinary team.

"The health professional has a narrowness of purpose which you need to have to do the task whereas I don't have to burden myself with that. I'm quite free. "PI

“Lived experience. It makes a huge difference I think. I've used this example a million times.....You know because once (the clients) perceive that person as someone in 
authority they kind of nod their head and smile but they're not really listening....you'd see ..... people nodding and smiling at doctors and nurses and you know that they're not taking anything in. Because they think, these people don't care, they're just doing their job, I'm just a number. "P2

This surety of purpose and emotional stability was further verbalised in the altruistic and compassionate motivation of some of the APSWs.

"It feels like a privilege really or feels like an honour like a, it's a bit of, it feels like a bit of karma, a bit of balancing the scales if you like because when I was 21 I was a menace to society according to a Crown Court Judge and now I am not a menace to society...."P1

The APSWs working in the enhanced role, reflect a resilient cohort in an advanced stage of their recovery journey. Their description of purpose, connection, emotional intelligence and perspective on their contribution are supported by the working model and opportunities offered by the programme.

I would say, self-belief. I wouldn't have thought I would have been able to handle sometimes pressure and sometimes stress as well and responsibility.

I do answer their phone calls because I feel that if they are calling me in this moment then I am important to them and I'm not supposed to but if they've got no-one else to call and they are calling me then it must be important and I think it helps with that relationship that I answer, I'm not just another person that is ignoring.

.... and I really like the direction and way that things are going and I really feel that my voice is being heard and that I'm an important part of the puzzle. I feel ... I'm not sure what the word is, but I do feel proud of it. (PP) 
The APSWs of the project are well informed and self-confident as they navigate the worlds of their clients and the healthcare providers. Their work extends beyond their personal journey to recover from adversity to advocate for their clients and improve access to services. This wider activity against the structural failures impacting access to healthcare reflects the elements of knowledge and change essential to the criticality and sustainability of their resilience.

\section{Discussion}

This case study exploration of the transition from PSW to APSW aimed to chart the enhanced experience of operating within the innovative inclusive care delivery model of HepCare. The findings have revealed a supportive programme structure as participants make the move between groups, supporting their employability and development of critical resilience (Arnstein et al 2002, Traynor 2017, Kennedy et al 2019).

The APSWs have lived experience of precarity and membership of an underserved population. That lived experience is vital for their effectiveness and role engaging with clients and negotiating their pathway through the healthcare maze. This positions the APSW at the interface of the 'street' and the 'institution' as they develop skills to navigate and interact in both worlds. Their position has been well received by the service users of this study and elsewhere (Norman et al 2008, Treloar et al 2015). Walsh et al (2018) exposed the 'dark side' of peer support as the potentially negative impact of exposing one's vulnerability of lived experience on future job opportunities. Yet the experience of the APSWs who openly and sensitively discussed issues of substance abuse, mental distress, homelessness and stigma in accessing health services was ownership of their experiences as a strength. The APSWs of this case study are committed to the task of supporting underserved clients to access healthcare as their right by extending their skills and practice remit. They all showed 
confidence in how they describe doing this, using their own experience of precarity as the foundation of their learning (Hammami 2016).

The role of peers has expanded in many healthcare settings, an area which traditionally has many hierarchies and polices on what certain roles can perform. As peers take on more advanced roles previously carried out by other health professionals, this can lead to conflict if not clearly defined (Bonnington \& Harris 2017). The APSW job description was co-designed between PSWs and nurses running the HepCare service to ensure feasible and realistic role development rather than an opportunity for task shifting (Mijovic et al 2016). Grading of the job description within the National Health Service Agenda for Change structure and hosting of the post within an NHS partner institution of the HepCare programme recognises the value of their role with remuneration. Some APSWs have permanent full time contracts, some are on 1 or 2 year contracts due to service commissioning structures within the UK. This model gives a structured space to develop their skills through the formalised Personal Development Review schedule, alongside access to occupational health support and other employee benefits. These structural benefits address the significant concerns in the peer support literature of supervision, support and career opportunities that can accompany peer support work (Mijovic et al 2016, Miler et al 2020).

In the workplace setting of HepCare, the peers were central to the clinical team; a team, which was multidisciplinary and had been working with peers over many years, thus making the integration, performance and support of the peer-led service less problematic.

The APSWs internalised sense of purpose to impact the barriers to health of the HepCare clients reflected their sense of belonging to this team. Once a person feels a valued member of the group, they internalize its purpose (Froese 2016). The shadowing or 'buddy' model of the HepCare APSW role induction supports learning of new members in a practical, on the 
job stepped approach guided by their confidence and learning needs. This inclusive approach has been linked with an increase in self-esteem and self-confidence in participants and recommended in other non-clinical worker training (Tavabie \& White 2020). Such connection and belonging to a team can support the freeing of oneself from focusing on the self and engendering a wider sense of purpose (Hennessy 2017).

Purpose itself, which in this study relates to supporting clients' access to hepatitis C treatment, has been shown to give direction, self-confidence and better wellbeing (Froese 2016). This sense of purpose in the APSWs of this study, facilitates the emerging identity of critical resilience. If resilience is viewed as an extension of coping (Liu et al 2017), critical resilience results in the individual informing themselves about restrictions and barriers, debating and discussing the context and implementing plans to effect change (Traynor 2017). In the context of the HepCare case study, the APSWs have accessed resources to inform themselves about the barriers in society that lead to the existence of precarity, effecting change through their work in advocacy and active support of clients in underserved populations to access services maximising their health and well-being. This advocacy and support offers purpose and meaning while integration into a new social group of care providers, buffered by the supportive context of the programme, facilitates a motivating sense of worth.

\section{Conclusion}

The HepCare model of inclusive working, promoting PSWs into an advanced remunerated role that capitalises on their ability to negotiate the street/institution interface, improves access to care for people of underserved populations and facilitates the development of critical resilience in the APSW. This model, therefore, offers tangible benefits to clients and 
to the APSW recovery journey and is replicable for other diseases and conditions which use the skills of people with lived experience.

\section{Policy Recommendations:}

1. Advanced Peer Workers require HCV training and a career pathway with appropriate salary to reflect their advanced role.

2. Individualised relapse prevention measures and support should be integrated into the APSW contract.

3. The promotion of advocacy and availability of support for APSWs should be facilitated through linkage to local, national and international networks.

4. Evidence based engagement with stakeholders in HCV treatment should guide policy makers in funding peer support.

\section{Acknowledgments}

We would like to thank our partner organisations' Groundswell and the Hepatitis C Trust for their help in developing and undertaking this project; Jim Conneely for his advocacy on behalf of people living with hepatitis C; the Find\&Treat team at UCLH NHS Trust; Vanessa Hack for project management support; The HepCare consortium and our funders the European Commission through its EU Third Health Programme (Grant Agreement Number 709844), and University College London and University College London Hospitals NHS Trust. 


\section{References}

Arnstein,P. Vidal,M. Wells-Federman,C. Morgan,B. Caudill,M. (2002) From chronic pain patient to peer: benefits and risks of volunteering. Pain Management Nursing 3: 3: 94-103 doi: 10.1053/jpmn.2002.126069

Bonnington,O. Harris,M. (2017) Tensions in relation: How peer support is experienced and received in a hepatitis $\mathrm{C}$ treatment intervention. International journal of drug policy. DOI: https://doi.org/10.1016/j.drugpo.2017.05.031

Damon,W. Callon,C. Wiebe,L. Small,W. Kerr,T. McNeil,R. (2017) Community-based participatory research in a heavily researched inner city neighbourhood: Perspectives of people who use drugs on their experiences as peer researchers. Social Science \& Medicine $176: 85 \mathrm{e} 92$

Devota,K. Woodhall-Melnik,J. Pedersen,C. et al (2016) Enriching qualitative research by engaging peer interviewers: A case study. Qualitative Research 16: 6: 661-680.

Froese,P. (2016) On Purpose: How we create the meaning of life. Oxford Scholarship Online/; Nov 2015. Accessed via Bodleian library $19^{\text {th }}$ Sept 2019.

Green,M. (2017) On the Inside Looking In: Methodological Insights and Challenges in Conducting Qualitative Insider Research. The Qualitative Report 19: 29: 1-13.

Greer,A. Bungay,V. Pauly,B. Buxton,J. (2020) 'Peer' work as precarious: A qualitative study of work conditions and experiences of people who use drugs engaged in harm reduction work. International Journal of Drug Policy 85 Doi: 10.1016/j.drugpo.2020.102922

Hammami,R. (2016) Precarious politics: The activism of 'bodies that count' (aligning with those that don't) in Palestine's colonial frontier in Butler,J. Gambetti,Z. Sabsay,L. (eds) Vulnerability in Resistance (p167-191) Duke University Press: London. 
Hegedus,A. Burr,C. Pfluger,V. Sieg,D. Nienaber,A. Schulz,M. (2020) Peer support worker training: Results of the evaluation of the Experienced Involvement training programme in Switzerland and Germany. International Journal of Mental Health Nursing doi: 10.1111/inm.12805

Hennessy,E.A. (2017) Recovery capital: A systematic review. Addiction Research and Theory. 25: 5: 349-60.

Jozaghi E, Greer AM, Lampkin H, Buxton JA (2018) Activism and scientific research: 20 years of community action by the Vancouver area network of drug users. Substance Abuse Treatment Prevention \& Policy 13(1):18.

Kerr T, Small W, Peace W, Douglas D, Pierre A, Wood E (2006) Harm reduction by a "userrun" organization: A case study of the Vancouver Area Network of Drug Users (VANDU). International Journal of Drug Policy 17(2):61-69.

Kennedy MC, Boyd J, Mayer S, Collins A, Kerr T, McNeil R (2019) Peer worker involvement in low-threshold supervised consumption facilities in the context of an overdose epidemic in Vancouver, Canada. Social Science \& Medicine 225:60-68.

Liu et al (2017) Advancing resilience: An integrative, multi-system model of resilience. Personality and Individual Differences 111 p111-118.

MacLellan, J. Surey,J, Abubakar,I. Stagg,H.R. (2015) Peer Support Workers in Health: A Qualitative Metasynthesis of Their Experiences. PLoS ONE. 10(10): p. e0141122.

Merriam,S.B. (1998) Qualitative research and case study applications in education. JosseyBass Publishers, San Francisco. 
Mijovic,H. McKnight,J. English,M. (2016) What does the literature tell us about health workers' experiences of task-shifting projects in sub-Saharan Africa? A systematic, qualitative review. Journal of Clinical Nursing 25: 2083-2100.

Miler JA, Carver H, Foster R, Parkes T (2020) Provision of peer support at the intersection of homelessness and problem substance use services: a systematic 'state of the art' review. $B M C$ Public Health 20(1):641.

Mowbray, C.T., D.P. Moxley, and M.E. Collins (1998) Consumers as mental health providers: First-person accounts of benefits and limitations. The Journal of Behavioral Health Services \& Research. 25(4): p. 397-411.

Mundeva,H. Snyder,J. Ngilangwa,D.P. Kaida,A. (2018) Ethics of task shifting in the health workforce: exploring the role of community health workers in HIV service delivery in lowand middle-income countries. BMC Medical Ethics 19: 71.

Norman, J., Walsh, N. M., Mugavin, J., Stoové, M. A., Kelsall, J., Austin, K., \& Lintzeris, N. (2008). The acceptability and feasibility of peer worker support role in community based HCV treatment for injecting drug users. Harm Reduction Journal, 5:1: 1.

Otte,I. Werning,A. Nossek,A. Vollman,J. Juckel,G. Gather,J. (2020) Challenges faced by peer support workers during the integration into hospital-based mental health-care teams: Results from a qualitative interview study. International Journal of Social Psychiatry 66:3: 263-269.

Sherman SG, Gann DS, Scott G, Carlberg S, Bigg D, Heimer R (2008) A qualitative study of overdose responses among Chicago IDUs. Harm Reduction Journal 5:1:2 
Simpson, A. Oster,C. Muir-Cochrane,E. (2018) Liminality in the occupational identity of mental health peer support workers: A qualitative study. International Journal of Mental Health Nursing 27: 2: 662-671.

Tavabie,J.A. White,P. (2020) Competency-based training for the noon-clinical workforce - A feasibility study, using a unique competency framework and career pathway. Education for Primary Care Doi: 10.1080/14739879.2020.1727779.

Traynor,M. (2017) Critical Resilience for Nurses. Routledge; London

Treloar, C., Rance, J., Bath, N., Everingham, H., Micallef, M., Day, C., Hazelwood, S., Grebely, J. \& Dore, G. J. (2015). Evaluation of two community-controlled 39 peer support services for assessment and treatment of hepatitis $\mathrm{C}$ virus infection in opioid substitution treatment clinics: The ETHOS study, Australia. International Journal of Drug Policy, 26(10), 992-998.

Walsh et al (2018) Understanding paid peer support. Disability in Society 33:4:579-597 